\title{
Evaluation of the Potential of Opuntia Ficus-Indica Cladodes as a Natural Flocculant for Wastewater Treatment through Simple Procedures
}

\author{
Sofia Trindade1', Maria Inês Rouxinol2 ${ }^{2}$ João Nabais ${ }^{3}$, Ana Cristina Agulheiro-Santos ${ }^{4 *}$ \\ 1 Master student, University of Évora, Portugal \\ 2 PhD student, Mediterranean Institute for Agriculture, Environment and Development, University of Évora, \\ Portugal \\ ${ }^{3}$ Comprehensive Health Research Center Departamento de Ciências Médicas e da Saúde, Escola de Saúde e \\ Desenvolvimento Humano, University of Évora, Portugal \\ ${ }^{4}$ Mediterranean Institute for Agriculture, Environment and Development, University of Évora, Portugal \\ * Corresponding author's e-mail: acsantos@uevora.pt
}

\begin{abstract}
Nowadays there is a search for new alternatives to replace harsh and expensive chemical methods to wastewater treatments. The common methods include the usage of chemicals that negatively affect the environment and the human health. The cladodes of Opuntia ficus-indica (L.) Mill have a great potential for use in innovative, cheap, renewable and eco-friendly water treatment due to their flocculant properties. In this work, different water treatments including fresh cladodes, lyophilized cladodes and the material obtained through mucilage extraction were tested. The turbidity of the water was measured, and it was concluded that the use of $60 \mathrm{~g}$ of small pieces of fresh cut cladodes was the method with the best results, reaching 4 NTU of turbidity. It confirmed the ability of $O$. ficus-indica (L.) Mill cladodes to promote the flocculation of clay in water, enabling to turn the unused material waste into a useful raw material.
\end{abstract}

Keywords: turbidity, wastewater treatments, flocculation, lyophilization, mucilage extractions.

\section{INTRODUCTION}

The Opuntia ficus-indica (L.) Mill cactus, known as prickly pear cactus, is a xerophyte plant widespread worldwide, growing in arid and semiarid zones. This plant shows a high ecological adaptability and can thrive in very diverse places with high temperatures, as extreme as $65^{\circ} \mathrm{C}$, with low water availability, which are very adverse conditions for many of the cultivated plants (Davis et al. 2019). The largest Opuntia genus is characterized by the Crassulacean Acid Metabolism (CAM), the plasticity of its plants being a major characteristic, exhibiting a high-water use efficiency, and the ability to store considerable quantities of water, which allows the plant to survive harsh environmental conditions, namely in arid areas. This metabolic pathway allows an adaptation to environmental conditions, an efficient hormone response activity, and a dramatic adaptation to circadian cue, resulting mainly in nocturnal $\mathrm{CO}_{2}$ fixation and daytime $\mathrm{CO}_{2}$ re-assimilation that allows photosynthetic carbon fixation under the conditions of limited water availability (Davis et al. 2019; Cushman \& Borland 2002). The Opuntia ficus-indica (L.) Mill is also adapted to soils classified as poor, with the values of $\mathrm{pH}$ near the neutrality, 6-7.5, but with a proper drainage, usual in sandy soils (Duarte and Paull, 2015). According to Arba et al. (2017) O. ficus-indica (L.) Mill is the cactus species with the highest degree of domestication and with the highest productivity values. Andreu-Coll et al. (2020) state that cactus pear cultivation could be a tool to mitigate climate change in arid regions, but could be also employed for rural development in European arid 
regions, like Mediterranean regions, e.g. Italy. Considering the rising concern for the declining water resources and climate changes, the culture of the O. ficus-indica (L.) Mill has been gaining relevance as an effective food production opportunity, in semi arid and arid regions. The composition of cladodes changes with the climatic conditions at the cultivation site, the season and the age of the plant (Stintzing \& Carle 2005), but their mucilage always contains galacturonic acid and different quantities of 1-arabinose, d-galactose, 1rhamnose, and d-xylose (Shlomo-Trachtenberg $\&$ Mayer 1980), in addition to dietary fiber and mineral elements, $\mathrm{Ca}^{2+}$ and $\mathrm{K}^{+}$responsible for the gelatinous properties (Sepúlveda et al. 2007). Beyond its use as food, this composition attributes a potential role as a natural flocculant to the cladodes and their mucilage. According to The United Nations World Water Development Report (2017) the vast majority of wastewater is neither collected nor treated. According to Miller et al. (2008) this mix of monomer sugars presented in the prickly pear cactus cladodes enhances the removal of turbidity. The more commonly used methods for wastewater treatment are coagulation/flocculation and these are employed when the deposition ratio is too slow to be considered effective. They are based on removing particles in suspension by destabilization and formation of larger and heavier flocs to ease deposition (Rachdi et al. 2017). Cladodes have the ability to flocculate the suspended particles in water, so they can reduce the use of the toxic aluminium sulfate in wastewater treatment (Bouaouine et al. 2019; Choumane et al. 2017; Choque-Quispe et al. 2020; Deshmukh \& Hedaoo 2019; Fedala et al. 2015; Fox et al. 2012; Miller et al. 2008; Rachdi et al. 2017). In addition to this physical cleaning role, and according to Deshmukh \& Hedaoo (2019), the microbiological load of water also decreases because the removal of fine suspended particles attracts as well as holds bacteria and viruses to their surface. Fox et al. (2012) reported that in the communities in the developing world, it is necessary to improve the accessible technologies to clean water, pointing out the arsenic removal from drinking water. As reported many years ago by Kirchmer et al. (1975), the results with the usage of mucilage were similar to those obtained with some synthetic polymers.

Although vegetable flocculants have already been tested in the past, they have been abandoned; however, some researchers state a bright future of their large-scale application (Zhang et al. 2006). Nowadays there is a new growing interest in restoring these methods, since the materials used are natural, biodegradable, can be easily found or produced and do not warm the environment or threaten the human health (Rachdi et al. 2017; Choumane et al. 2017). These raw materials are well adapted in underdeveloped countries, often with scarce availability of clean water. An adult plant of Opuntia ficus-indica (L.) Mill has an average production of 250 cladodes, leading to 625 $\mathrm{kg}$ per plant, making this natural product vastly abundant (Andreu-Coll et al. 2020). The orchards of prickly pear cactus produce large quantities of cladodes; most of them are pruned and wasted. Developing different uses for the cladodes will create value, potential to raise farmer's income and economic viability of this culture from a circular economy perspective, but also from a watersaving perspective, and adaptation to very poor soils, comparing to other crops.

In this exploratory research work, different methods to use cladodes as flocculant in the process of cleaning the water with clay, reducing the turbidity, were tested, including fresh cladodes, lyophilized cladodes and the material obtained through different mucilage extractions methods. There is a new interest in finding affordable and environmentally non-aggressive wastewater treatments to reduce or even end, the use of chemicals that have adverse effects on human health, for more sustainable treatment of wastewater in developed countries where the pernicious effect of aluminum is already known and in undeveloped countries that often fight against water scarcity.

This research seeks the most effective and simple methods for using prickly pear cladodes, or their mucilage, to treat wastewater.

\section{MATERIALS AND METHODS}

\section{Preparation of fresh cladodes samples}

The cladodes tested in this study were harvested in a plantation of autochthonous varieties in Alentejo, south of Portugal, Latitude: 38.74000562683715 , Longitude: -7.815030812780606 that is conducted in organic production system.

For sample preparation, the fresh adult cladodes were cut into small pieces of $1.5 \mathrm{~cm}$ by $1 \mathrm{~cm}$. This raw material was used for further preparation of another different modality. 


\section{Preparation of lyophilized cladodes}

Small pieces of cladodes underwent the lyophilisation process. Two kinds of samples were obtained: one constituted of small lyophilized pieces and another obtained thought the lyophilization of cladodes and posterior grinding into a powder, so that it could also be used in the test. The lyophilized cladodes are easy to transport and store, allowing a long period of use.

\section{Cladodes juice extractions}

Two kinds of mucilage extraction were performed, a heat extraction and a cold one. For the heat extraction, $500 \mathrm{~g}$ of cut cladodes were set into a glass bowl with $1 \mathrm{~L}$ of tap water, and then was placed on a hot plate, so that the mixture of cladodes and water could boil for $1 \mathrm{~h}$ at $80^{\circ} \mathrm{C}$. After that process, the recipient was left to cool and then the content was coarsely filtered.

For the cold extraction, the same number of cut cladodes was used but the extraction was performed with $1.5 \mathrm{~L}$ of cold water. The water and the cladodes were added to a bowl and set aside for 24 hours, at the end of that period the contents of the recipient were filtered.

\section{Test conditions}

The test was carried out using glass bowls filled with $500 \mathrm{ml}$ of tap water and $5 \mathrm{~g}$ of clay; a magnetic stirrer was used in two different stirring speeds. Firstly, the clay was mixed in the water in high speed for $5 \mathrm{~min}$ to ensure that the contents of the bowl were mixed properly. Subsequently, the water turbidity was analyzed for the first time. Then, the cladodes were added to the mixture before a new and slower stirring speed has been applied for $10 \mathrm{~min}$, and afterwards the turbidity was measured once again. At the end of this process, the glass bowls were set aside with the turbidity being monitored strictly every 5 minutes and photos were taken using a stereo microscope.

In the test with the fresh cladodes, the three different quantities tested were $40 \mathrm{~g}, 60 \mathrm{~g}$ and $80 \mathrm{~g}$; while in the test with the lyophilized cladodes, the quantities were calculated to be the equivalent of the fresh ones used previously. Therefore, the corresponding values obtained for lyophilized cladodes were $2.824 \mathrm{~g}, 4.236 \mathrm{~g}$ and $5.648 \mathrm{~g}$, respectively. These tests lasted for 1-hour, after the second stirring was complete.
The use of lyophilized powder required a previous step that consisted of rehydrating the powder, trough the addition of $5 \mathrm{~g}$ of the powder to $50 \mathrm{ml}$ of water, so that a rehydration could occur. That substance obtained has been added to the mixture of water and clay just before the second stirring. In both, the heat and cold extractions, the quantity added to their borosilicate glass bowl was $5 \mathrm{~g}$. For the control proposes, one identic glass bowl was left with only the mixture of water and clay and monitored.

\section{Specific equipment}

Turbidity was analyzed using a turbidimeter (Canadawide Scientific Model 800), the results were expressed in NTU (Nephelometric Turbidity Unit).

The stereo microscope used was a LEICA MZ12.5 equipped with a LEICA EC3 camera. This stereo microscope provides a three-dimensional visualization of the sample with low magnification ranges from $8-100 \times$.

\section{RESULTS}

\section{Pieces of fresh cladodes}

A marked increase in water transparency was noticeable in all the cases, which fresh cladodes were included, when compared with control. It was clear that there was a more intense decrease of turbidity in the water containing $60 \mathrm{~g}$ of fresh cladodes (Fig. 1). The turbidity values in the bowl that contain $40 \mathrm{~g}$ of cladodes decrease in a gradual way until a stable point. The quantity of cladodes might have a limit regarding their flocculation capacity. The bowl containing $80 \mathrm{~g}$ of cladodes, exhibited a decreasing in the water turbidity, but comparing with the one with $60 \mathrm{~g}$, it was evident that this change stopped sooner. This might mean that using too many cladodes can cause saturation of the water with mucilage. On the other hand, the modality with $40 \mathrm{~g}$ of cladodes never reached the same low values as the other two modalities, 60 $\mathrm{g}$ and $80 \mathrm{~g}$. Therefore, there should have an optimum level of mucilage to obtain the best results in decreasing the values of turbidity.

In all the methods tested, there was a great decreasing in turbidity during the first 5 minutes of the test. The bowl containing $60 \mathrm{~g}$ of cladodes had the fastest decreasing in turbidity levels, reaching 


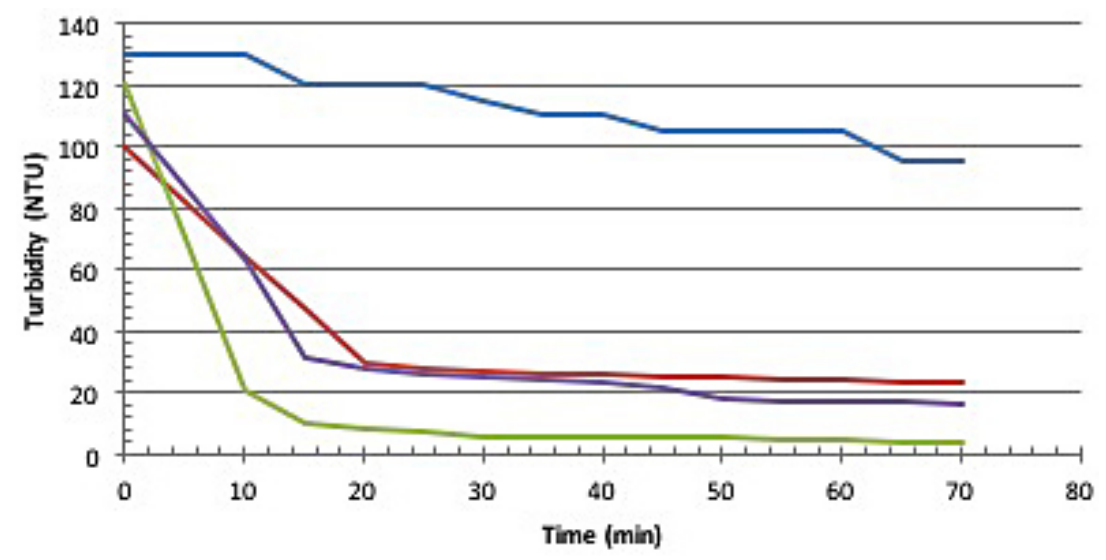

Figure 1. Turbidity curves (NTU) observed over time of the experiment in the solution of water with clay and the addition of different quantities (40 g, $60 \mathrm{~g}, 80 \mathrm{~g}$ ) of pieces of fresh cladodes and a control modality without addition

the value of $20 \mathrm{NTU}$ after 10 minutes of test, the first baseline. The bowl containing $40 \mathrm{~g}$ of cladodes reached the first baseline also at $10 \mathrm{~min}$ utes, but with a higher turbidity level, 60 NTU. The bowl containing $80 \mathrm{~g}$ of cladodes seemed to reach the first baseline later, approximately 30 NTU. There was a second decrease of the turbidity observed, but not as drastic as the first one. For about 20 minutes after the beginning of the test, the bowls with $40 \mathrm{~g}$ and $80 \mathrm{~g}$ of cladodes had turbidity levels near $30 \mathrm{NTU}$, and showed a slight decrease until the 45 minutes. The bowl containing $60 \mathrm{~g}$ of cladodes had the most satisfactory behavior, with an earlier and constant decreasing during the test, reaching the values close to 0 NTU. The control modality after one hour remains with values higher than 100 NTU.

In the photos concerning the modality with the $60 \mathrm{~g}$ of fresh cladodes (Fig. $6-1,2,3$ ), an evolution in the amount and size of particles in suspension can be obseerved that reduces as flocculation occurs. In the first photo without cladodes (Fig. 6 - control) there is a large quantity of particles in suspension; however, 10 minutes after the cladodes were added (Fig. $6-$ 1) there was a very noticeable difference in the number of particles and after 30 minutes (Fig. $6-3$ ) when the water turbidity reached a point of stabilization, the particles in suspension were smaller and much less.

\section{Lyophilized cladodes: small portions and powder}

The first step observed in this experiment was the hydration process of the lyophilized powder that caused an initial increase in the values of turbidity (Fig. 2), before the start of the flocculation process. As a result of this process, there was a decrease of the water volume inside the bowl, so there was an increase in the values of the turbidity since all the previous water to clay ratios were disturbed. The hydration process extends for the first 15 minutes of the experiment; afterwards, it was possible to observe a reduction in the turbidity. Although the bowl contained $2.824 \mathrm{~g}$ of cladodes, after $25 \mathrm{~min}$., when the values of turbidity start to diminish, they never reached the values below 140 NTU, higher than the control sample. At the end of the experiment, it was clear that there was a small difference between the results from the glass bowl with the $5.648 \mathrm{~g}$ and the one with $4.236 \mathrm{~g}$. When compared to the results obtained with the fresh cladodes, it was also clear that the lyophilized cladodes were not as efficient as the fresh ones. The lyophilization process itself, can cause some damages on the molecular structures, implying a loss of compounds responsible for the flocculation ability. The cell wall is likely to be damaged in the process, since it is in essence a dehydration process, meaning that water is removed from the cells. According to Morgan et al. (2006), this hypothesis is valid since one of the conclusions they stated was that lyophilization causes loss of cell viability.

The photos of the experiment were taken, including the bowl containing $80 \mathrm{~g}$ of lyophilized cladodes (Fig. $6-4,5,6$ ), enabling to see an interesting appearance of the mixture after 10 minutes (Fig. $6-4$ ), and at the end of the test there were fewer particles in suspension and, 


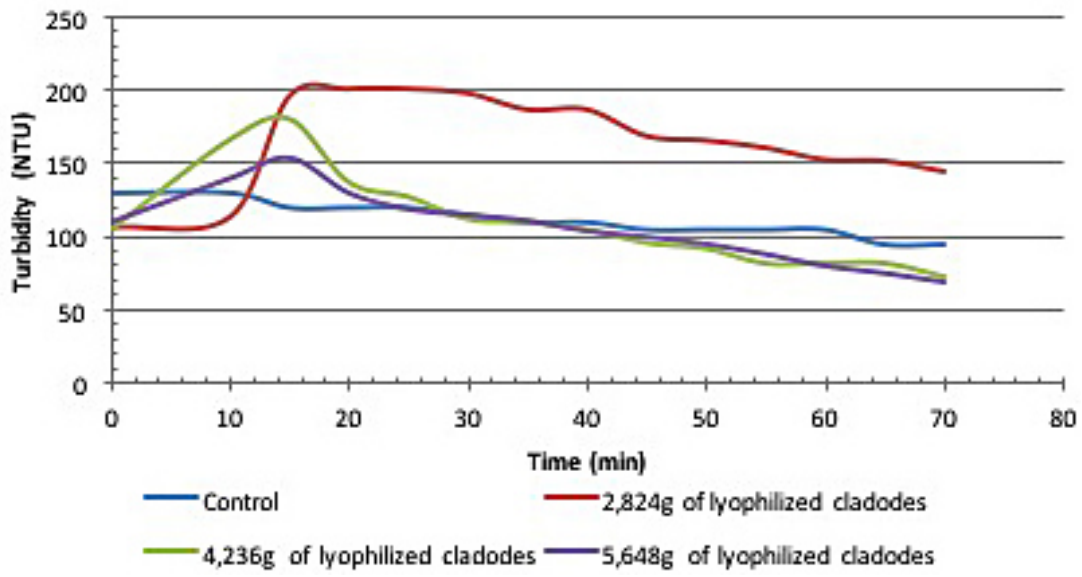

Figure 2. Turbidity curves (NTU) observed over time of the experiment in the solution of water with clay and the addition of different quantities of fresh lyophilized cladodes and a control modality without addition

once again, the particles still left in suspension were smaller. This difference in the size of the particles is noticeable, comparing the photo taken after 30 minutes (Fig. $6-5$ ) with the one at the end of the test (Fig. $6-6$ ).

The use of lyophilized powder reached much better results (minimum $40 \mathrm{NTU}$ ) of turbidity and faster (50 NTU after 20 minutes) than the small pieces of lyophilized cladodes (higher than $120 \mathrm{NTU}$ after 20 minutes) (Fig. 3). From a practical point of view, this modality of lyophilized powder presents the advantage of large storage time and easy transportation; however, the final use is difficult because the powder will form clusters of mucilage and clay that will remain in the suspension in the water, making their removal harder.

The photos (Fig. $6-7,8,9$ ) prove that the quantity of particles in the suspensions after the addition of the lyophilized powder is lesser than those in the previous photos with $80 \mathrm{~g}$ of lyophilized pieces of cladodes. The powder also appears to be able to cause the flocculation of smaller particles, unlike the fresh cut cladodes and the lyophilized cut cladodes. However, it is possible to see threads of the previously mentioned clusters of mucilage and clay in suspension, especially in the last two photos.

\section{Mucilage obtained by heat extraction}

It is possible to observe that using mucilage obtained by heat extraction, after $25 \mathrm{~min}$ utes the turbidity has reached a value of 20 NTU. This value was only overpassed by the result obtained using $60 \mathrm{~g}$ of fresh cladodes (Fig. 4). This test had a shorter duration (40 minutes) because after 25 minutes the value of turbidity remained stable. The modality of using mucilage obtained by heat extraction

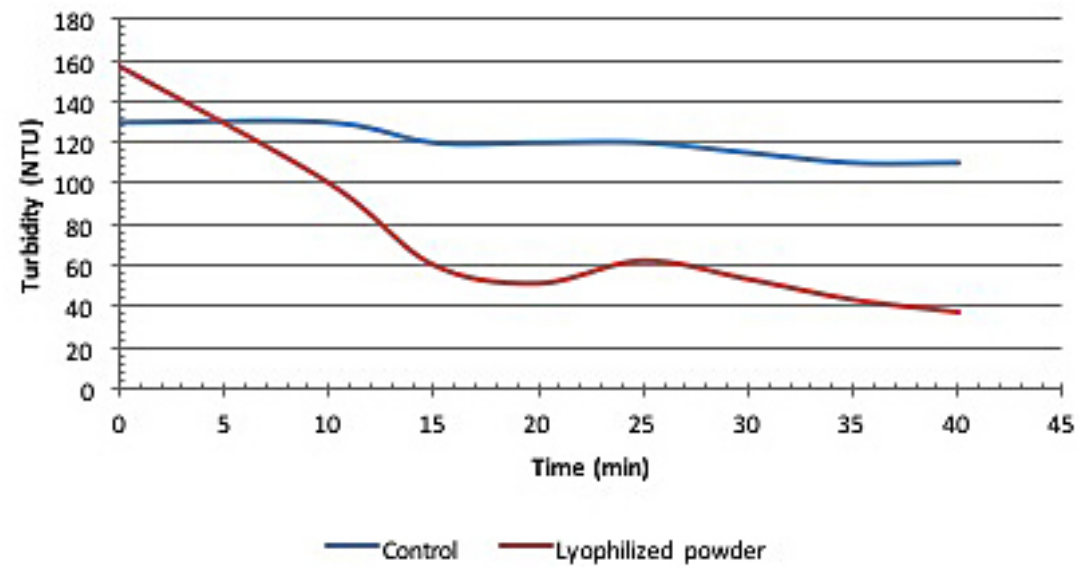

Figure 3. Turbidity curves (NTU) observed over time of the experiment in the solution of water with clay and the addition of lyophilized powder extraction and a control modality without addition 


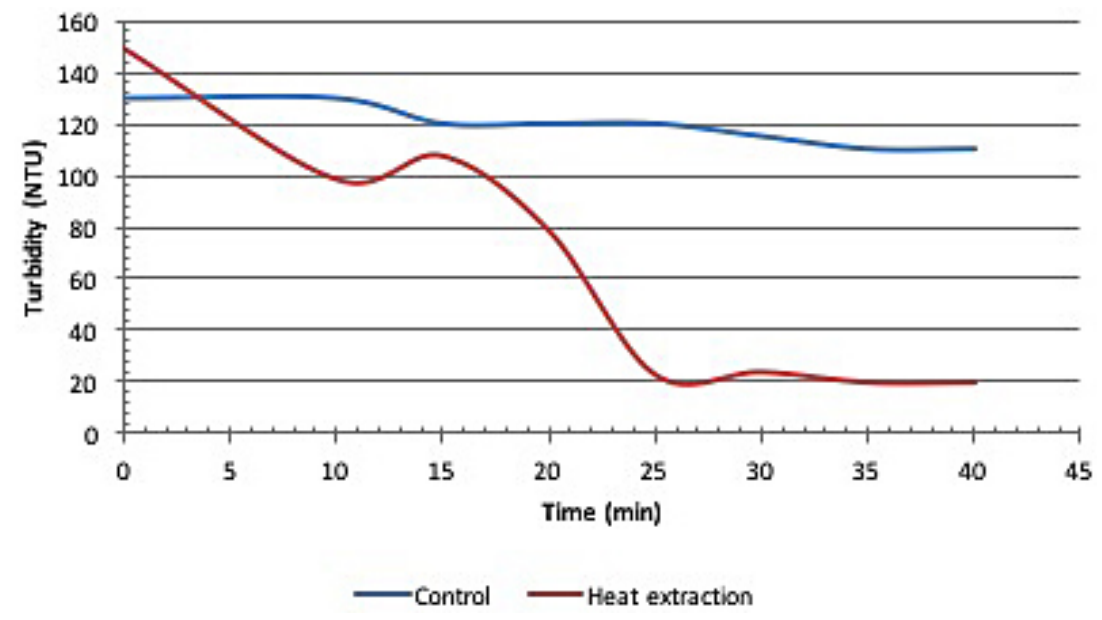

Figure 4. Turbidity curve (NTU) observed over time of the experiment in the solution of water with clay and the addition of mucilage obtained by heat extraction and a control modality without addition

presented good results, proving to be faster and more efficient than the other methods of extraction tested.

The photos taken during this test (Fig. $6-$ $10,11,12)$, showed the reduction in the number of particles in suspension, mainly the large particles and only remained fewer particles of smaller dimensions, just like happened in the test with the lyophilized powder. However, it is possible to see, especially in the last photo (Fig. $6-12$ ) that parts of the mucilage remain in suspension in the water, similarly to what happened with the clusters of mucilage and clay in the test with the powder. This mucilage in suspension could be the reason why the results obtain in this test were not as good (minimum 20 NTU) as those obtained with the fresh cladodes (minimum 4 NTU).

\section{Mucilage extracted by cold extraction}

The results obtained (Fig. 5) with the use of the mucilage extracted using the method of cold extraction was of 50 NTU of turbidity, after 30 minutes, while the result of modality with the mucilage of heat extraction at the same time was of 24 NTU. However, the simplicity of this cold mucilage extraction method must be emphasized. Moreover, this mucilage can be easy stored with good characteristics for long time which seems to be an added value and was noticeable during this study.

The observation of the photos (Fig. $6-13$, $14,15)$ could testify that the cold extraction of the mucilage does not show as much improvement in the water turbidity as the mucilage obtained trough heat extraction, as it was previously stated, highlighting the fact that the mucilage

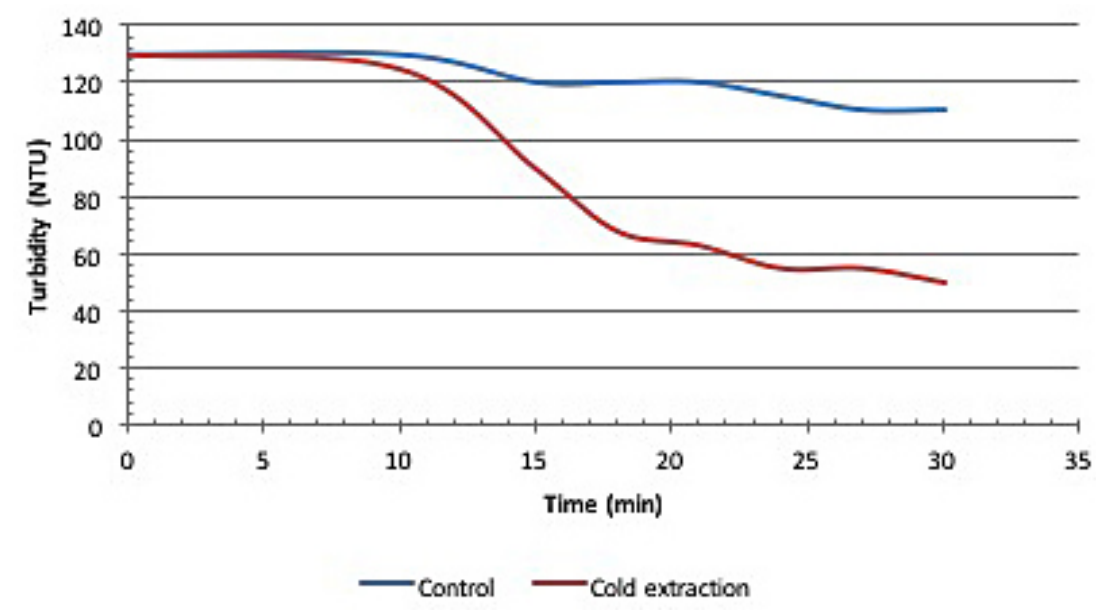

Figure 5. Turbidity curve (NTU) observed over time of the experiment in the solution of water with clay and the addition of mucilage obtained by cold extraction and a control modality without addition 


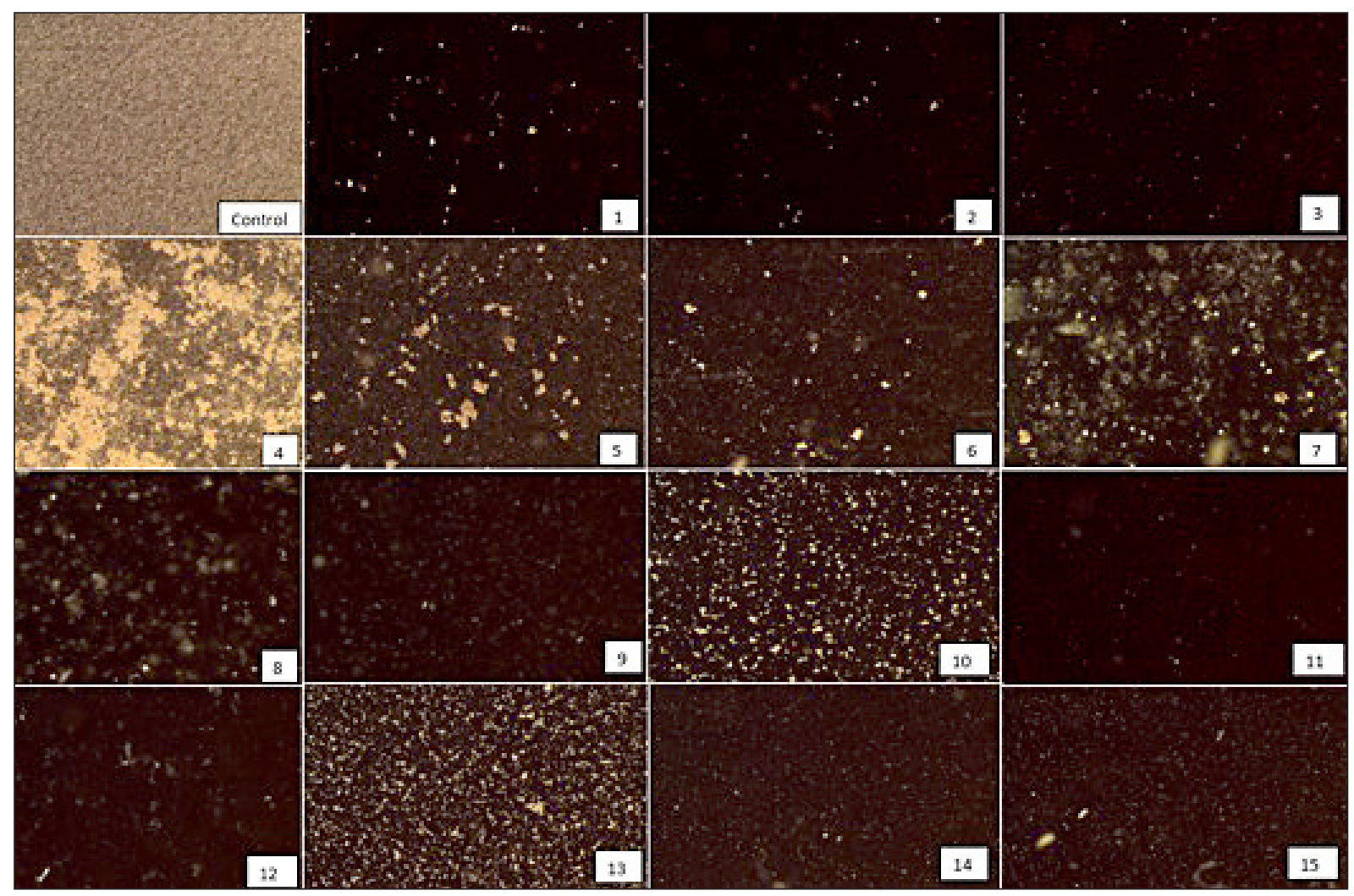

Figure 6. Visible evolution of the presence of particles of clay in the water throughout the different tests, by using a stereo microscope that provides a three-dimensional visualization of the sample with a magnification of $25 \mathrm{x}$. Photo, 1 - control, represents the solution without cladodes. The photos 1, 2, 3 concern the modality with the 60 $\mathrm{g}$ of fresh cladodes, respectively 10 minutes, 30 minutes after the cladodes were added to the solution and at the end of the experiment. The photos 4, 5, 6 were taken of the modality of $80 \mathrm{~g}$ of lyophilized cladodes added to the clay solution, respectively 10 minutes, 30 minutes after the cladodes were added to the solution and at the end of the experiment. The photos 7, 8, 9 concern the addition of lyophilized powder, respectively 10 minutes after, 30 minutes after and at the end of the experiment. The photos 10,11, 12 were took during the test with mucilage obtained by heat extraction, respectively 10 minutes, 30 minutes after the mucilage was added to the solution and at the end of the experiment. The photos 13,14, 15 concern the use of the mucilage extracted by cold extraction, 10 and 30 minutes after the addition, and at the end of the experiment.

obtained by heat extraction was more efficient, faster and achieved lower values.

\section{DISCUSSION}

Underlining the fact that we managed to obtain a turbidity of 20 NTU with the mucilage obtained by heat extraction, and by using fresh cladodes the values of turbidity were much lower, 5 NTU, seems to be very promising results when compared to results the reported by Rachdi et al. (2017) who tested pure cladode juice and the results obtained were not satisfactory. However, in the same work, the usage of juice with aluminium sulfate induced good results in removing wastewater residues. During that experiment, it was necessary to add $1.0 \mathrm{~g} / \mathrm{L}$ of aluminium sulphate to the fresh cladode juice to obtain a value of 20,5 NTU.

Batatache et al. (2014) used an Algerian variety of $O$. ficus-indica (L.) Mill juice as a natural flocculant for sewage sludge, and they found that the optimum dosage was $0.4 \mathrm{~g} \cdot \mathrm{kg}^{-1}$ of dry matter, and $2.5 \mathrm{NTU}$ of turbidity was the minumum value reached, very similar to the results obtained with different polyelectrolytes: Chimfloc C4346, a cationic polymer, Sedipur NF 102, a non-ionic polymer and Sedipu AF 400, an anionic polymer, and inorganic conditioners, $\mathrm{FeCl}_{3}$ and $\mathrm{Al}_{2}\left(\mathrm{SO}_{4}\right)_{3}$.

The best results obtained by Zhang et al. (2006) were similar to those we obtained using pieces of fresh cladodes. The work published by that team using milled and sieved cladodes as raw coagulate to treat surface water, observed a decrease from 104 NTU to less than 5 NTU. The 
authors also reached to the conclusion that there is an optimum dosage of cladodes, according to their results it was around $60 \mathrm{mg} / \mathrm{L}$, a quite smaller dose than we have used. This difference can be attributed to the preparation of the cladodes, but also to the water alkalinity and temperature since in their study they found that these parameters can influence the results obtained.

Other studies have shown that in order to achieve higher effectiveness, the natural polymers such as the cladodes of the Opuntia cactus can be used in conjunction with metal coagulants (Bratby 2016).

It must be enphasized that the chemical composition of cladodes varies considerably among cultivars, age of the cladode, climate (temperature and rainfall) and soil conditions (Mounir et al. 2020); thus, it is necessary to test each raw material itself. We consider the results obtained in this research work valid for these regional variety and these particular edafo-climatic conditions.

Regarding our visual observations during the experiments and the photos made with the stereo microscope, we can conclude that the lyophilized powder of cladodes and both mucilage extractions appear to have the ability to cause the flocculation of particles of smaller dimensions, unlike the fresh and lyophilized cut cladodes which seem to be unable to cause the flocculation of smaller particles. Nevertheless, the powder and mucilage by both extraction methods were difficult to remove from the water after the conclusion of the test and they all leave traces of mucilage in suspension in the water.

\section{CONCLUSION}

This work aimed to quantify the capability of Opuntia ficus-indica (L.) Mill cladodes to act as a natural flocculant. Moreover the best method and quantity to promote flocculation were chosen thus decreasing turbidity in water with clay. The turbidity of the water was measured, which allowed us to reach the conclusion that the use of $60 \mathrm{~g}$ of small pieces of fresh cut cladodes was the method with the best results, reaching 4 NTU, to remove the clay impurities from the water, in this controlled environment and using this variety produced under this specific climatic condition. It should be emphasized that this method only requires preparation of the material, by cutting it into small portions. The results obtained with this method were closely followed by those of mucilage got by heat extraction method that reached 20 NTU. All the methods tested confirmed the observation of other authors, about the ability of $O$. ficus-indica (L.) Mill cladodes to promote the flocculation of clay in water and to contribute to the water treatment process. It is advisable to make this method available to clean water in a sustainable way, especially in the countries that produce prickly pear, being possible to turn this waste into a useful raw material.

\section{Acknowledgments}

The authors thanks to PepeAromas, a local producer from Portugal, Alentejo, that supplied the cladodes for this research.

\section{REFERENCES}

1. Andreu-Coll, L., Cano-Lamadrid, M., Noguera-Artiaga, L., Lipan, L., Carbonell-Barrachina, Á.A., Rocamora-Montiel, B., Legua, P., Hernández, F., López-Lluch, D., 2020. Economic estimation of cactus pear production and its feasibility in Spain. Trends Food Science \& Technology, 103 (September 2020), 379-385. https://doi.org/10.1016/j. tifs.2020.07.003

2. Betatache, H., Aouabed, A., Drouiche, N., Lounici, H., 2014. Conditioning of sewage sludge by prickly pear cactus (Opuntia ficus Indica) juice. Ecological Engineering, 70, 465-469.https://doi.org/10.1016/j. ecoleng.2014.06.031

3. Bouaouine, O., Bourven, I., Khalil, F., Bressollier, P., Baudu, M., 2019. Identification and role of Opuntia ficus indica constituents in the flocculation mechanism of colloidal solutions. Separation and Purification Technology, 209 (July 2018), 892-899. https://doi.org/10.1016/j.seppur.2018.09.036

4. Bratby, J., 2016. Coagulation and Flocculation in Water and Wastewater Treatment. 3rd edition. IWA Publishing. ISBN electronic: 9781780407500 https://doi.org/10.2166/9781780407500

5. Choumane, F.Z., Benguella, B., Maachou, B., Saadi, N., 2017. Valorisation of a bioflocculant and hydroxyapatites as coagulation-flocculation adjuvants in wastewater treatment of the steppe in the wilaya of Saida (Algeria). Ecological Engineering, 107, 152159. https://doi.org/10.1016/j.ecoleng.2017.07.013

6. Choque-Quispe, D., Ramos-Pacheco, B. S., Ligarda-Samanez, C.A., Barboza-Palomino, G.I., Kari-FerroA., Taipe-Pardo, F., Choque-Quispe, Y., 2020. Heavy metal removal by biopolymersbased formulations with native potato starch/nopal 
mucilage. Revista Facultad de Ingeniería Universidad De Antioquia. https://doi.org/10.17533/udea. redin. 20201112

7. Cushman, J.C, Borland, A.M., 2002. Induction of Crassulacean acid metabolism by water limitation. Plant Cell Environ., (Feb 2002) 25(2), 295-310. doi: 10.1046/j.0016-8025.2001.00760.x.PMID: 11841671

8. Davis, S.D., Simpson, J., Gil-Vega, K.C., Niechayev, N.A., Tongerlo, E., Castano, N.H., Dever, L.V., Búrquez, A., 2019. Undervalued potential of crassulacean acid metabolism for current and future agricultural production. Journal of Experimental Botany, 70(22), 6521-6537. https://doi:10.1093/jxb/erz223

9. Deshmukh, S.O., Hedaoo, M.N., 2019. Wastewater Treatment Using Bio-Coagulant as Cactus Opuntia Ficus Indica. 2nd International Conference on New Frontiers in Chemical, Energy and Environmental Engineering (INCEEE-2019) 15-16 Feb 2019, NIT Warangal, India.

10. Duarte, O., Paull, R.E., 2015. Exotic fruits and nuts of the new world. Chapter 2 In: Calophyllaceae, Clusiaceae and Cactaceae. CABI, Wallinford, United Kingdom.

11. Fox, D.I., Pichler, T., Yeh, D.H., Alcantar, N.A., 2012. Removing Heavy Metals in Water: The Interaction of Cactus Mucilage and Arsenate. Environmental Science \& Technology, 46 (8), 4553-4559. https://doi: 10.1021/es2021999

12. Kirchmer, C.J., Arboleda, J.V, Castro, M.L., 1975. Polimeros naturales y su aplicacion como ayudantes de floculacion. Serie Documentos Tecnicos, 2, Centro Panamerica Ingenieria y Ciences del Ambiente, Lima, Peru.

13. Miller, S.M., Fugate, E.J., Craver, V.O., Smith, J.A., Zimmerman, J.B., 2008. Toward understanding the efficacy and mechanism of Opuntia spp. as a natural coagulant for potential application in water treatment. Environmental Science \& Technology,
42(12), 4274-4279. doi: 10.1021/es7025054. PMID: 18605544 .

14. Mounir, B., Younesa, E.G., Asmaaa, M., Abdeljalila Z., Abdellaha, A., 2020. Physico-chemical changes in cladodes of Opuntia ficus-indica as a function of the growth stage and harvesting areas. Journal of Plant Physiology., 251 (August 2020), 153196. https://doi.org/10.1016/j.jplph.2020.153196

15. Morgan, C.A., Herman, N., White, P.A., Vesey, G., 2006. Preservation of micro-organisms by drying; A review. Journal of Microbiological Methods, 66(2), 183-193. https://doi.org/10.1016/j. mimet.2006.02.017

16. Rachdi, R., Srarfi, F., Shimi, N.S., 2017. Cactus Opuntia as natural flocculant for urban wastewater treatment. Water Science and Technology, 76(7), 1875-1883. https://doi.org/10.2166/wst.2017.370

17. Stintzing, F.C., Carle, R., 2005. Cactus stems (Opuntia spp.): A review on their chemistry, technology, and uses. Molecular Nutrition and Food Research., 49(2), 175-194. https://doi.org/10.1002/ mnfr.200400071

18. Sepúlveda, C., Sáenz, E., Aliaga, Aceituno, C., 2007. Extraction and characterization of mucilage in Opuntia spp. Journal of Arid Environments, 68, 534545. https://doi.org/10.1016/j.jaridenv.2006.08.001

19. Shlomo Trachtenberg, A. Mayer M., 1980. Biophysical properties of Opuntia ficus-indica mucilage. Phytochemistry, 21(12), 2835-2843 https:// doi.org/10.1016/0031-9422(80)85052-7

20. WWAP - United Nations World Water Assessment Programme, 2017. The United Nations World Water Development Report 2017. Wastewater: The Untapped Resource. Paris, UNESCO. SBN 978-92-3-100201-

21. Zhang, J., Zhang, F., Luo, Y., Yang, H., 2006. A preliminary study on cactus as coagulant in water treatment. Process Biochemistry, 41(3), 730-733. https://doi.org/10.1016/j.procbio.2005.08.016 